\title{
Geometric parameter optimization of magneto-rheological damper using design of experiment technique
}

\author{
S K Mangal ${ }^{*}$ and Ashwani Kumar
}

\begin{abstract}
Background: Magneto-rheological (MR) damper is one of the most promising semi-active devices. The MR dampers offer a reliability of a passive system yet maintain the versatility and adaptability of the fully active control devices.

Methods: In this paper, an optimization process is developed to optimize the geometrical parameters of an MR damper using finite element method (FEM) coupled with Taguchi approach which is rarely available in the literature. The damping force of the MR damper is selected as an objective function. To achieve this objective, 18 FEM models, based on Taguchi orthogonal array, are developed on ANSYS platform.

Results: These results have been analyzed by using the design of experiment (DoE) methodology and an optimized solution is then arrived. The optimal solution is validated experimentally as well as through FEM for $95 \%$ confidence level. These results are found to be in good agreement with each other.

Conclusions: This paper establishes that numerical technique results, e.g., FEM, can be used over the real experimental results for the geometric parameter optimization of an MR damper. The proposed methodology will save time and resources for designing an optimized MR damper for automotive and other applications.
\end{abstract}

Keywords: Optimization; Magneto-rheological damper; Finite element method; Taguchi technique; Design of experiment; Geometric parameters

\section{Background}

Smart materials are the materials having multiple tunable properties. These material properties are significantly altered in a controlled and reversible manner by some external stimuli, e.g., current, electric, or magnetic fields, etc (Ashwani and Mangal 2012). Magneto rheological fluid (MRF) is one of such smart materials. The discovery of the MR fluids is credited to Jacob Rabinow in 1948 at the US National Bureau of Standard (Rabinow 1948). Excellent features of the MRF technology, e.g., fast response, simple interface between electrical power input and mechanical power output, and precise controllability, make it most attractive for many industrial applications. These features have triggered considerable research activities on the modeling and design of MR devices, e.g., dampers, valves, clutches, and brakes, etc. When this

\footnotetext{
* Correspondence: skmangal_pec@rediffmail.com

Mechanical Engineering Department, PEC University of Technology,
} Chandigarh 160012, India technology is employed for an automotive damper, it gives a variable damping coefficient which mainly depends on the intensity of the magnetic field induced. This makes vibration control/isolation effective over a wide frequency spectrum and is more useful in a real practical sense. A typical magneto-rheological damper consists of cylinder, piston, excitation coil, and the MR fluid which is enveloped in a cylinder. The MR valves and dampers are designed analytically (Zhu et al. 2012; Wei et al. 2003) as well as using finite element method ( $\mathrm{Li}$ and Guo 2003; Parlak et al. 2012). An analytical optimization design method is also proposed (Rosenfield and Werely 2004) for the MR valves and dampers which are based on the assumption of constant magnetic flux density throughout the magnetic circuit. In the analysis (Rosenfield and Werely 2004), it has been assumed that one region of the magnetic circuit does not saturate prematurely. As the valve performance not only depends on the magnetic circuit but also on the geometry of the ducts through which

\section{实}


the MR fluid passes, the above assumption has led to a sub-optimal solution. One, thus, can say that the research on optimal design of an MR damper is still in its nascent age.

The objective of this paper is to optimize geometric parameters of an MR damper to have its optimized damping performance. The optimization of the MR damper is based on the design of experiment (using Taguchi methodology) and finite element method which is rarely available in the literature. Based on the critical literature survey, four geometric parameters of the MR damper, which influences the damping force the most are selected. Based on Taguchi methodology, $\mathrm{L}_{18}$ orthogonal array $(\mathrm{OA})$ is selected. As the authors have found that the FEM results were in good agreement with the experimental results (Ashwani Kumar et al. 2014; Ashwani and Mangal 2014), the response parameter, i.e., damping force of the MR damper as obtainable by the FEM, is employed in the Taguchi technique in place of the real experimental results. Further, the use of the FEM-based modeling saves the cost of optimization process. The response parameter of these models is analyzed in the ANOVA to get an optimized solution. The confirmation experiment of the optimized MR damper is performed by fabricating the MR damper with optimized geometric parameters as obtained by design of experiment (DoE) analysis. The field-dependent damping force for the optimized damper is determined by the FEM (on ANSYS platform) as well as experimentally. The confirmation experiment on the optimized MR damper is found to have good conformity with the optimal design results for $95 \%$ confidence level. The main contribution of this paper is to establish the approach of optimization of the MR damper geometry with the sole objective of maximizing the damping force using DoE technique and finite element analysis. The optimization process proposed here has used the numerical technique results, e.g., FEM over the real experimental results in the optimization process and saved time and resources for designing of an optimized MR damper.

\section{Methods}

\section{Modeling and experimental studies of an MR damper}

While modeling of an MR damper, it is assumed that the magnetic loop is formed only in the magnetic material and magnetic flux leakage is negligible in it. According to the magnetic Ohm's law, the magnetic circuit parameters are magnetic reluctance, $R_{i}(\mathrm{AT} / \mathrm{WB})$, magnetic flux, $\phi(\mathrm{WB})$, and magnetic potential, $F(\mathrm{AT})$. Their relationship is given as

$$
F=R_{i} \phi
$$

where $F$ is magnetic potential and is also given as $N I$, where $N$ is the number of coil turns and $I$ is the current passed through the coil. The magnetic reluctance, $R_{i}$, is given as

$$
R_{i}=\frac{L_{i}}{\mu_{i} A_{i}}
$$

where the $L_{\dot{v}} A_{i}$, and $\mu_{i}$ are the length (mean path of magnetic flux lines in the component), cross sectional area of the component, and permeability of $i$ th element of the magnetic flux path, respectively. The magnetic flux, $\phi$, and magnetic flux density, $B$, are given by:

$$
\phi=\frac{N I}{R_{T}}, B=\frac{\phi}{A},
$$

where the $R_{T}$ is the total reluctance of the magnetic path. According to the structural design, one gets a typical magnetic loop for the MR damper (Figure 1). After a critical literature survey, the various dimensions of an MR damper prototype are selected and are shown in Table 1. The magnetic flux density $(B)$ of the designed magnetic circuit is calculated for different current levels for the MR damper.

For the FEM modeling, the MR damper is an axisymmetric solid subjected to axi-symmetric loading. A 2D FEM modeling is, thus, selected for its analysis through the ANSYS platform. The piston, MR fluid gap, and the cylinder are assumed to be stationary component, and it completes the magnetic circuit around the coil. In the modeling, 350 turns are wrapped over the piston to make it electromagnet and to calculate the magnetic flux. The MR damper is modeled on the ANSYS platform to calculate its magnetic flux density in the clearance space of the damper. The relationship between the magnetic flux density $(B)$ and yield shear stress $\left(\tau_{y}\right)$ for the LORD MRF122EG (www.lord.com) fluid is to be determined to evaluate the damping force. To determine this relationship, data is extracted from the technical graphs supplied by the LORD ${ }^{\circ}$ Corp. Inc., Cary, USA (www.lord.com). Using curve fitting techniques of MATLAB software, relationship between yield shear stress $\left(\tau_{y}\right)$ and magnetic flux density $(B)$ for the fluid is determined. The corresponding cubical polynomial as obtained by the MATLAB software is given as

$$
\begin{aligned}
\tau_{y}= & \left(6.9 \times 10^{2}\right)+\left(4 \times 10^{4}\right) B-\left(1 \times 10^{5}\right) B^{2} \\
& +\left(9.1 \times 10^{4}\right) B^{3}
\end{aligned}
$$

Thereafter, using the magnetic flux density as determined in the above modeling, the corresponding values of the yield shear stress is thus determined.

According to Bingham plastic model, based on the plate modeling (Carlson et al. 1995; Zhao-Dong 2012; Engineering Note-Designing with MR Fluids), the total damping force, $F_{D}$, is the sum of an induced 


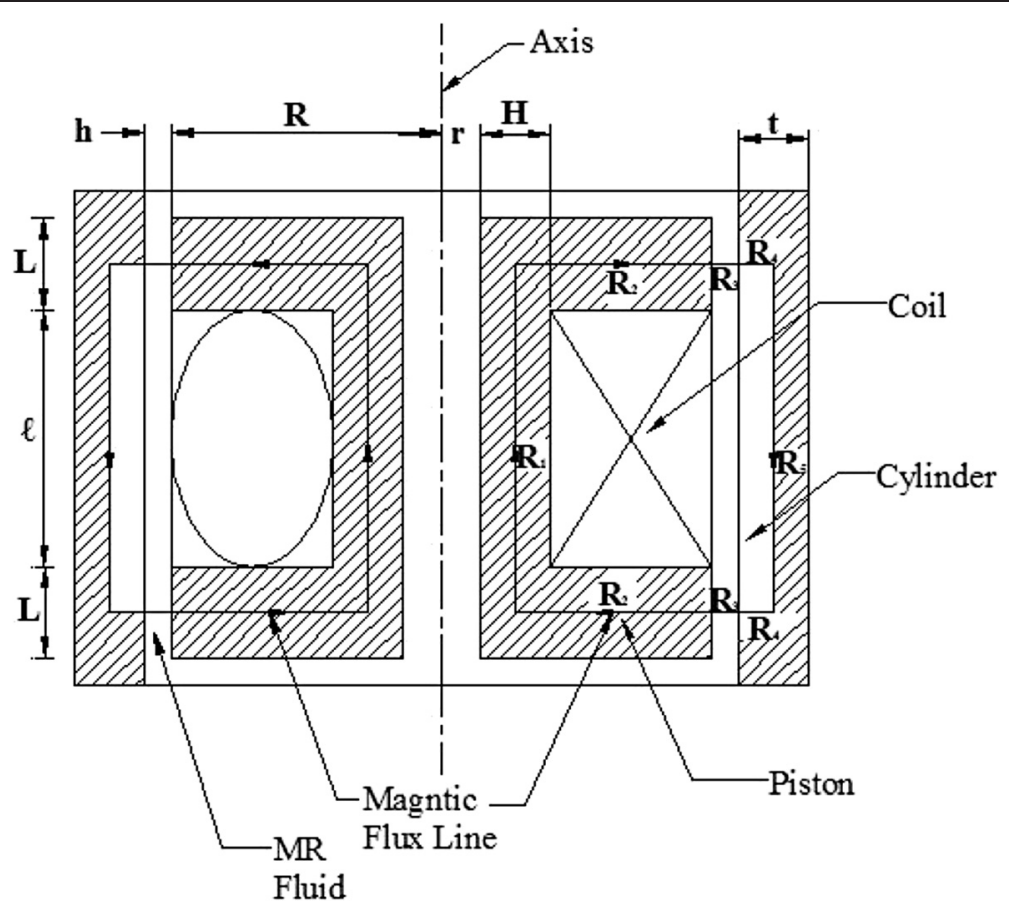

Figure 1 Typical magnetic loop of an MR damper.

yield stress component, $F_{\tau}$, and viscous components, $F_{\eta}$, is given as

$$
\begin{aligned}
F_{D}=F_{\tau}+F_{\eta}= & \left(2.07+\frac{12 Q \eta}{12 Q \eta+0.4 w h^{2} \tau_{y}}\right) \frac{\tau_{y} L A_{p}}{h} \operatorname{sgn}(v) \\
& +\left(1+\frac{w h v}{2 Q}\right) \frac{12 \eta Q L_{t} A_{p}}{w h^{3}}
\end{aligned}
$$

where

$$
\begin{aligned}
& Q=A_{p} \times v \\
& A_{p}=\frac{\pi}{4}\left(D^{2}-d_{o}^{2}\right),
\end{aligned}
$$

Table 1 Dimensions of a prototype MR damper

\begin{tabular}{llc}
\hline $\begin{array}{l}\text { Serial } \\
\text { number }\end{array}$ & Parameter & $\begin{array}{c}\text { Dimensions } \\
(\mathbf{m m})\end{array}$ \\
\hline 1 & Pole length $(L)$ & 23 \\
2 & Distance between the poles $(\ell)$ & 22 \\
3 & Radius of the piston $(R)$ & 23 \\
4 & Piston rod radius $(r)$ & 06 \\
5 & Radial distance from piston rod to coil width $(H)$ & 07 \\
6 & Clearance between piston and cylinder $(h)$ & 01 \\
7 & Thickness of the cylinder $(t)$ & 08 \\
\hline
\end{tabular}

(Ashwani Kumar et al. 2014). where $Q$ is the volumetric flow rate, $A_{p}$ is the effective cross-sectional area of piston, $D$ is the diameter of the piston, $d_{0}$ is the diameter of the piston $\operatorname{rod}, v$ is the piston velocity, $\tau_{y}$ is the yield shear strength of the MR fluid, $\eta$ is the off-state (no magnetic field) viscosity of the MR fluid, $L$ is the effective axial pole length, $h$ is the gap between piston and cylinder, $L_{t}$ is the total axial pole length, $w$ is the mean circumference of the damper's annular flow path, and $\operatorname{sgn}(v)$ is used to consider the reciprocating motion of the piston. Total damping force of the FEM model is thus calculated using Equation 5 and is tabulated quantitatively in the second column of Table 2 .

Based on the above modeling (Ashwani Kumar et al. 2014; Ashwani and Mangal 2014), an MR damper is fabricated of the dimensions as listed in Table 1. The LORD MRF-122EG (www.lord.com) MR fluid is used in the fabricated damper for evaluating its performance (Ashwani Kumar et al. 2014). The input current supplied to the MR damper is varied using Wonder Box kit provided by LORD $^{\circ}$ Corp. Inc., Cary, USA (www.lord.com). The experimental damping force for different input currents as experienced by the damper is tabulated in the third column of Table 2 . These results are found to be matching well with the FEM results.

\section{Results and discussion}

Scheme of experiments and optimization

A design based on Taguchi methodology is developed with the objective of maximizing the damping force of 
Table 2 FEM and experimental damping force of an MR damper prototype

\begin{tabular}{lcc}
\hline $\begin{array}{l}\text { Current } \\
\text { (A) }\end{array}$ & $\begin{array}{c}\text { Total damping force - FEM } \\
\text { model (N) }\end{array}$ & $\begin{array}{c}\text { Total damping force - } \\
\text { experimental (N) }\end{array}$ \\
\hline 0.10 & 206.38 & 224.40 \\
0.20 & 303.20 & 327.66 \\
0.30 & 371.95 & 394.36 \\
0.40 & 418.33 & 436.77 \\
0.50 & 448.02 & 463.14 \\
0.60 & 466.67 & 481.73 \\
0.70 & 480.06 & 504.65 \\
\hline
\end{tabular}

(Ashwani Kumar et al. 2014; Ashwani and Mangal 2014).

the damper. During this optimization process, the values of geometric parameters of the damper that yields the maximum damping force are determined. The geometric parameters are searched between lower and upper bounds.

Selection of orthogonal array and parameter assignment As listed in Table 1, there are seven basic geometric parameters of an MR damper which affect the magnetic flux density and subsequently the damping force. Based on the exhaustive literature survey, four parameters, which affect the damping force the most, are selected. These four critical geometrical parameters came out as pole length $(L)$, radial distance from piston rod to coil width $(H)$, clearance between piston and cylinder $(h)$, and thickness of the cylinder $(t)$.

In an optimization, if the non-linear behavior exists among the parameters, then it can only be studied if more than two levels are selected for these parameters. As suggested by Ross (Ross 1988) and Roy (Roy 1990), the number of parameters and their interactions and the number of levels for the parameters are considered while selecting the $\mathrm{L}_{18} \mathrm{OA}$. This array is used in conducting the optimization experiment. In this optimization studies, Taguchi's mixed level design is selected as it has been decided to keep two levels for thickness of cylinder and the three levels for other three geometric parameters. These four input parameter range is shown in Table 3. In order to evaluate the influence of these four critical damper parameters on the damping force (response parameter), the experiments are designed and conducted by Taguchi methodology. The ANOVA analysis is performed to ascertain the statistically important parameters which influences the response parameter the most.

The damping force is ideally be determined by conducting real experimental studies for the $\mathrm{L}_{18} \mathrm{OA}$. The fabrication and experimental testing of the $18 \mathrm{MR}$ dampers as suggested by $\mathrm{L}_{18} \mathrm{OA}$ is neither economical (as it increases the cost of experimentation) nor feasible (as it is time consuming). This in turn would have defeated the very basic purpose of obtaining an optimized solution economically. FEM is usually carried out worldwide to reduce the actual experimentation cost. Moreover, the authors have found that the FEM results are in good agreement with the experimental results. Because of the above facts, the FEM result of the MR dampers is used to get the response parameters for the $\mathrm{L}_{18} \mathrm{OA}$.

It has further been observed in the literature that magnetic flux density lines at different current values to the electromagnet do not cross among themselves and show a monotonic behavior (Chang-sheng 2003). Because of these facts, the optimization process can be carried out at any arbitrary input current value. During the present study of optimization, the analysis is carried out at $0.1 \mathrm{~A}$ current for the 18 FEM-based MR damper models. Table 4 shows the damping force as evaluated by FEM modeling on ANSYS platform.

\section{Selection of optimal levels for parameters}

The Design Expert ${ }^{\text {tw }}$ software is used for analyzing the above raw response data and also to get the vital data regarding the model. To determine which factors are significantly affecting the response characteristics, i.e., damping force, analysis of variance (ANOVA) is carried out. The ANOVA summary and the percentage contribution of each parameter is tabulated in Table 5. From Table 5, it is observed that the maximum percentage, i.e., $66.46 \%$, in the response characteristics of the design model, is contributed by factor D, i.e., clearance between piston and cylinder $(h)$. It means that this factor is the most critical factor in designing of the magnetic circuit/MR damper. While the minimum percentage, i.e., $1.16 \%$, in the designed model, is contributed by factor A, i.e., thickness of cylinder $(t)$ and thus it is the least significant factor for the design of an MR damper. The other two factors B and D, i.e., pole length $(L)$

Table 3 Input parameters and their range

\begin{tabular}{|c|c|c|c|c|c|}
\hline \multirow{2}{*}{$\begin{array}{l}\text { Serial } \\
\text { number }\end{array}$} & \multirow[t]{2}{*}{ Parameter } & \multirow{2}{*}{$\begin{array}{c}\text { Parameter } \\
\text { name }\end{array}$} & Lower range & Mid range & Upper range \\
\hline & & & \multicolumn{3}{|c|}{ Dimensions (mm) } \\
\hline 1 & Pole length $(L)$ & A & 18 & 23 & 28 \\
\hline 2 & Radial distance from piston rod to coil width $(H)$ & B & 05 & 07 & 09 \\
\hline 3 & Clearance between piston and cylinder $(h)$ & C & 0.8 & 1.0 & 1.2 \\
\hline 4 & Thickness of the cylinder ( $t$ ) & $\mathrm{D}$ & 06 & - & 08 \\
\hline
\end{tabular}


Table 4 The $\mathrm{L}_{18}\left(2^{1} * 3^{7}\right)$ OA (parameters assigned) with a response parameter

\begin{tabular}{|c|c|c|c|c|c|}
\hline \multirow[t]{2}{*}{ Run } & \multicolumn{5}{|c|}{ Factors } \\
\hline & $\begin{array}{l}\text { Thickness of } \\
\text { cylinder }(\mathrm{mm})\end{array}$ & $\begin{array}{l}\text { Pole length } \\
(\mathrm{mm})\end{array}$ & $\begin{array}{l}\text { Radial distance from piston rod to } \\
\text { coil width }(\mathrm{mm})\end{array}$ & $\begin{array}{c}\text { Clearance between piston and } \\
\text { cylinder }(\mathrm{mm})\end{array}$ & $\begin{array}{c}\text { Damping force calculated } \\
\text { using ANSYS (N) }\end{array}$ \\
\hline & (A) & (B) & (C) & (D) & $(\mathrm{Y} 1)$ \\
\hline 1 & 6 & 18 & 5 & 0.8 & 216.81 \\
\hline 2 & 6 & 18 & 7 & 1 & 164.11 \\
\hline 3 & 6 & 18 & 9 & 1.2 & 127.73 \\
\hline 4 & 6 & 23 & 5 & 0.8 & 262.26 \\
\hline 5 & 6 & 23 & 7 & 1 & 195.52 \\
\hline 6 & 6 & 23 & 9 & 1.2 & 150.01 \\
\hline 7 & 6 & 28 & 5 & 1 & 232.26 \\
\hline 8 & 6 & 28 & 7 & 1.2 & 183.49 \\
\hline 9 & 6 & 28 & 9 & 0.8 & 318.92 \\
\hline 10 & 8 & 18 & 5 & 1.2 & 138.38 \\
\hline 11 & 8 & 18 & 7 & 0.8 & 213.13 \\
\hline 12 & 8 & 18 & 9 & 1 & 199.35 \\
\hline 13 & 8 & 23 & 5 & 1 & 204.34 \\
\hline 14 & 8 & 23 & 7 & 1.2 & 161.97 \\
\hline 15 & 8 & 23 & 9 & 0.8 & 298.53 \\
\hline 16 & 8 & 28 & 5 & 1.2 & 191.52 \\
\hline 17 & 8 & 28 & 7 & 0.8 & 295.99 \\
\hline 18 & 8 & 28 & 9 & 1 & 253.58 \\
\hline
\end{tabular}

and radial distance from piston rod to coil width $(H)$, are having $26.97 \%$ and $3.05 \%$ percentage contribution, respectively. The complete ANOVA summary table giving the $F$ value and the vital data is shown in Table 6. The Model $F$ value of 59.26 implies that the model being analyzed is a significant one. There is only a $0.01 \%$ chance that a 'Model $F$ value' larger than the above can occur due to the noise. The values of 'Prob $>F$ less than 0.0500 indicate model parameters which are significant. In the performance analysis of MR damper, B, C, and D parameters came out to be the significant model parameters. The values of 'Prob $>F$ greater than
0.1000 indicate the model parameters are insignificant and thus parameter A came out to be insignificant. From Table 6, the 'Pred R-squared' is of 0.9237 which is in reasonable agreement with the 'Adj R-squared', i.e., 0.9600. The 'Adeq precision' measures the signal to noise ratio. In the analysis, the signal to noise ratio comes out 24.515 which indicates an adequate signal and the model can be used to navigate the design space.

The optimization of the MR damper model is then performed with the help of the Design Expert software by selecting the above listed geometric parameters and

Table 5 ANOVA summary of percentage contribution

\begin{tabular}{lccccc}
\hline Parameter & Term & DOF & Sum of squares & Mean square & Percentage contribution \\
\hline Model & $\mathrm{A}$ & 1 & 620.54 & 620.54 & 1.16 \\
Model & $\mathrm{B}$ & 2 & $14,441.85$ & $7,220.92$ & 26.97 \\
Model & $\mathrm{C}$ & 2 & $1,634.83$ & 817.41 & 3.05 \\
Model & $\mathrm{D}$ & 2 & $35,586.23$ & $17,793.11$ & 66.46 \\
Error & $\mathrm{E}$ & 2 & 459.28 & 229.64 & 0.86 \\
Error & $\mathrm{F}$ & 2 & 230.15 & 115.08 & 0.43 \\
Error & $\mathrm{G}$ & 2 & 155.48 & 77.74 & 0.29 \\
Error & $\mathrm{H}$ & 2 & 189.71 & 94.85 & 0.35 \\
Error & $\mathrm{AB}$ & 2 & 225.72 & 112.86 & 0.42 \\
\hline
\end{tabular}


Table 6 Complete ANOVA summary and vital data

\begin{tabular}{cccccc}
\hline Source & Sum of squares & DF & Mean square & F value & Prob $>\boldsymbol{F}$ \\
\hline Model & $52,283.45$ & 7 & $7,469.06$ & 59.26 & $<0.0001$ \\
A & 620.54 & 1 & 620.54 & 4.92 & 0.0508 \\
B & $14,441.85$ & 2 & $7,220.92$ & 57.29 & $<0.0001$ \\
C & $1,634.83$ & 2 & 817.41 & 6.49 & 0.0156 \\
D & $35,586.23$ & 2 & $17,793.11$ & 141.18 & $<0.0001$ \\
Residual & $1,260.35$ & 10 & 126.03 & & Significant \\
Cor total & $53,543.79$ & 17 & & & \\
\hline
\end{tabular}

R-squared = 0.9765; Adj R-squared = 0.9600; Pred R-squared = 0.9237; Adeq precision = 24.515.

their levels. The goal of the optimization is to maximize the damping force of the damper. The optimized solution for the response parameter as provided by the software is given in Table 7 .

\section{Estimation of optimum performance characteristics}

The value of the geometric parameters of the MR damper for its optimal damping force came out to be as follows: Thickness of cylinder (A, second level) $=8 \mathrm{~mm}$, Pole length $(\mathrm{B}$, third level $)=28 \mathrm{~mm}$, Radial distance from piston rod to coil width $(\mathrm{C}$, third level $)=09 \mathrm{~mm}$, and Clearance between piston and cylinder $(\mathrm{D}$, first level $)=0.8 \mathrm{~mm}$. The optimum value of the total damping force $(\mathrm{N})$ is predicted at the above selected levels of the parameters, i.e., $A_{2} B_{3} C_{3} D_{1}$. The estimated mean of the response characteristic (damping force) (Ross 1988; Roy 1990) is then determined as

$$
\bar{\mu}_{\text {Damping Force }}=\overline{\mathrm{A}}_{2}+\overline{\mathrm{B}}_{3}+\overline{\mathrm{C}}_{3}+\overline{\mathrm{D}}_{1}-3 \times \overline{\mathrm{T}}
$$

where $\overline{\mathrm{T}}$ : overall mean of damping force $=211.55 \mathrm{~N}, \overline{\mathrm{A}}_{2}$ : average damping force at the second level of thickness of the cylinder $=217.42 \mathrm{~N} ; \overline{\mathrm{B}}_{3}$ : average damping force at the third level of pole length $=245.96 \mathrm{~N}, \overline{\mathrm{C}}_{3}$ : average damping force at the third level of radial distance from piston rod to coil width $=224.69 \mathrm{~N}, \overline{\mathrm{D}}_{1}$ :

Table 7 Optimized geometric parameters and solution for the MR damper

\begin{tabular}{llc}
\hline $\begin{array}{l}\text { Serial } \\
\text { number }\end{array}$ & Factor & Dimensions \\
\hline 1 & Factor A: thickness of cylinder $(t)$ & $8 \mathrm{~mm}$ \\
2 & Factor B: pole length $(L)$ & $28 \mathrm{~mm}$ \\
3 & $\begin{array}{l}\text { Factor C: radial distance from piston rod to } \\
\text { coil width }(H)\end{array}$ & $9 \mathrm{~mm}$ \\
4 & Factor D: clearance between piston and & $0.8 \mathrm{~mm}$ \\
5 & cylinder $(h)$ & $321.03 \mathrm{~N}$ \\
6 & Damping force & 1.00 \\
\hline
\end{tabular}

average damping force at the first level of clearance between piston and cylinder $=267.61 \mathrm{~N}$. Substituting these parameter values in Equation 8, one gets the estimated mean of the response characteristic, i.e., damping force $(\mathrm{N})$ as

$$
\begin{aligned}
\bar{\mu}_{\text {Damping Force }}= & 217.42+245.96+224.69+267.61 \\
& -3 \times 211.55 \\
= & 321.03 \mathrm{~N}
\end{aligned}
$$

The $95 \%$ confidence interval of confirmation experiments $\left(\mathrm{CI}_{\mathrm{CE}}\right)$ and of population $\left(\mathrm{CI}_{\mathrm{pop}}\right)$ is calculated (Ross 1988) as

$$
\begin{aligned}
& \mathrm{CI}_{\mathrm{CE}}=\sqrt{F_{\alpha}\left(1, f_{e}\right) V_{e}\left[\frac{1}{n_{e f f}}+\frac{1}{R}\right]} \\
& \mathrm{CI}_{\text {pop }}=\sqrt{\frac{F_{\alpha}\left(1, f_{e}\right) V_{e}}{n_{e f f}}}
\end{aligned}
$$

where $\alpha$ is the risk, $F_{\alpha}\left(1, f_{e}\right)$ is the $F$ ratio at the confidence level of (1- $\alpha$ ) against DOF, i.e., 17 and error DOF $\left(f_{e}\right) 10, N$ is the total number of results, i.e., 18 (treatment $=18$ and repetition $=1), R$ is the sample size for confirmation experiments, and $V_{e}$ is the error variance, i.e., 126.03 .

The effective sample size $\left(n_{\text {eff }}\right)$ is applied to the treatment conditions being estimated and is given as

$$
\begin{aligned}
n_{\text {eff }} & =\frac{\mathrm{N}}{1+\left[\begin{array}{l}
\text { Total DOF associated with } \\
\text { items used in mean response }
\end{array}\right]} \\
& =\frac{18}{1+7}=2.25
\end{aligned}
$$

The tabulated $F$ value $\left(F_{0.05}(1,10)\right)$ is 4.96 (Ross 1988) at $95 \%$ confidence level, i.e., 1- $\alpha$. Substitution of the 
Table 8 Total damping force comparison for the optimized MR damper

\begin{tabular}{lccc}
\hline $\begin{array}{l}\text { Current } \\
\text { (A) }\end{array}$ & $\begin{array}{c}\text { Total damping } \\
\text { force - FEM } \\
\text { model (N) }\end{array}$ & $\begin{array}{c}\text { Total damping force - } \\
\text { experimental (N) }\end{array}$ & $\begin{array}{c}\text { Percentage error } \\
\text { of experimental } \\
\text { results with } \\
\text { relation to FEM } \\
\text { one }\end{array}$ \\
\hline 0.10 & 314.18 & 331.20 & 5.42 \\
0.20 & 476.26 & 501.81 & 5.37 \\
0.30 & 583.67 & 609.79 & 4.48 \\
0.40 & 649.10 & 668.99 & 3.06 \\
0.50 & 688.12 & 707.99 & 2.89 \\
0.60 & 712.92 & 731.40 & 2.59 \\
\hline
\end{tabular}

above values in Equations 10 and 11 gives the values for confidence interval of confirmation experiments $\left(\mathrm{CI} \mathrm{CE}_{\mathrm{C}}\right)$ and of population $\left(\mathrm{CI}_{\text {pop }}\right)$ which are given as

$$
\begin{aligned}
& \mathrm{CI}_{\mathrm{CE}}=\sqrt{4.96 \times 126.03\left[\frac{1}{2.25}+\frac{1}{1}\right]}= \pm 30.05 \\
& \mathrm{CI}_{\mathrm{POP}}=\sqrt{\frac{4.96 \times 126.03}{2.25}}= \pm 16.67
\end{aligned}
$$
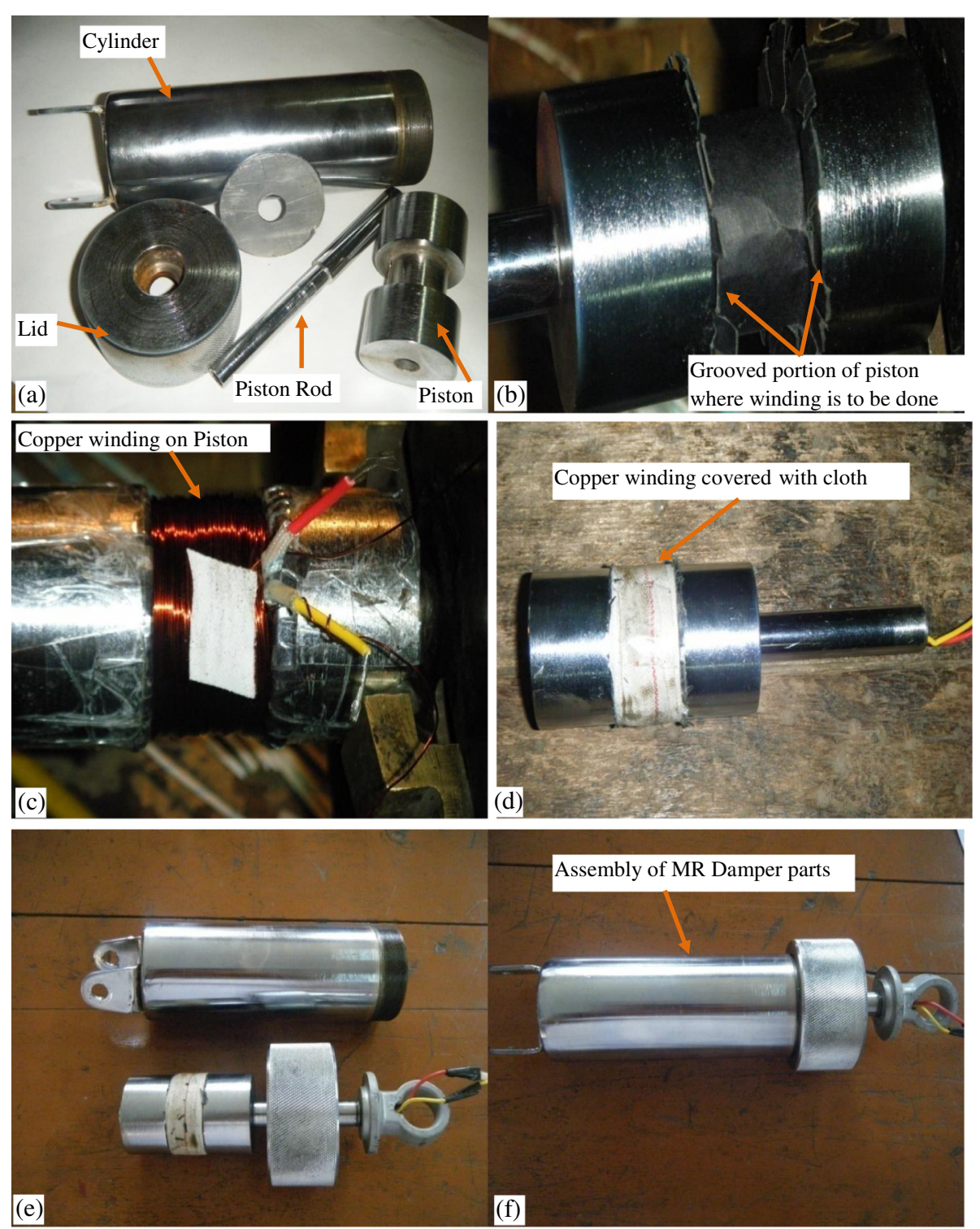

Figure 2 The various components of the MR damper. (a) Components of the optimized MR damper. (b) Grooved portion of piston with insulator material. (c) Assembled piston and its rod with copper winding. (d) Copper winding covered with a cloth. (e) Assembly of piston, piston rod, and lid. (f) Complete assembly of the optimized MR damper. 
The predicted optimal range for the damping force based on confidence interval of confirmation experiments $\left(\mathrm{CI}_{\mathrm{CE}}\right)$ is given as

$$
\begin{aligned}
\mu_{\text {Damping Force }}-\mathrm{CI}_{\mathrm{CE}} & <\mu_{\text {Damping Force }}<\mu_{\text {Damping Force }}+\mathrm{CI}_{\mathrm{CE}} \\
290.98 & <\mu_{\text {Damping Force }}<351.07
\end{aligned}
$$

The $95 \%$ conformation interval of the predicted mean of the damping force for confidence interval of population $\left(\mathrm{CI}_{\text {pop }}\right)$ is given as

$$
\begin{gathered}
\mu_{\text {Damping Force }}-\mathrm{CI}_{\text {pop }}<\mu_{\text {Damping Force }}<\mu_{\text {Damping Force }}+\mathrm{CI}_{\text {pop }} \\
304.36<\mu_{\text {Damping Force }}<337.69
\end{gathered}
$$

\section{Modeling of optimized MR damper}

After optimizing the significant MR damper parameters, the FEM modeling and the experimental study are performed and are illustrated in this section.

\section{FEM modeling}

The optimized MR damper is modeled by the FEM on ANSYS platform in a similar manner as illustrated above and the total damping force is then determined for the model. The total damping force is shown in the second column of Table 8 .

\section{Experimental testing}

Based on the optimization results, an optimized MR damper is fabricated. The various components of the MR damper are shown in Figure 2. The optimized MR damper is experimentally tested for its damping performance by using the MR fluid (LORD MRF-122EG). The input current is varied from $0.1 \mathrm{~A}$ to $0.6 \mathrm{~A}$ in a step of $0.1 \mathrm{~A}$.

\section{Confirmation experiment}

The purpose of the confirmation experiment is to validate the conclusions drawn by the ANOVA analysis. A confirmation experiment for the damping force is conducted at the optimum setting of the geometric parameters on the ANSYS platform. The confirmation experimental value of damping force is found to be $314.18 \mathrm{~N}$ by the FEM modeling and $331.20 \mathrm{~N}$ by experimental testing at $0.1 \mathrm{~A}$ current level. Both these values of the damping force fall within the $95 \%$ confidence interval of the predicted optimum response parameters (Equations 15 and 16). It, thus, validates the optimization process and results obtained in this paper. Table 8 also shows the total damping force as obtained by FEM and experimental studies for other different input current values. From the table, the error in the damping force of the FEM model is found to be within the $5.50 \%$ of the experimental value which is in good agreement to each other. The comparison between the FEM and experimental results for the optimized damper is shown qualitatively in Figure 3.

\section{Conclusions}

In this paper, the optimization of geometric and response parameters of an MR damper using statistical tools coupled with FEM is presented. The geometric parameters are searched between lower and upper bounds having two/three levels for each of these parameters. The FEM models in accordance with Taguchi's methodology based on orthogonal array $\left(\mathrm{L}_{18} \mathrm{OA}\right)$ are developed on ANSYS platform for the MR damper at $0.1 \mathrm{~A}$. The results are statistically analyzed using ANOVA to determine the optimal geometric parameters. From the ANOVA analysis, it is concluded that the working clearance between piston and cylinder $(h)$ parameter showed the maximum contribution for the damping force while pole length $(L)$ and radial distance from piston rod to coil width $(H)$ parameters are found to have intermediate contribution and the cylinder thickness $(t)$ parameter had the least contribution for the optimization process. The optimized solution of the damper given by the optimization process is tested experimentally as well as through FEM for 95\% confidence level at $0.1 \mathrm{~A}$. The results on the optimized damper conformed well to the optimal design results (as given by the DoE). It, thus, validated the proposed model of optimization of damping force for an MR damper.

This paper demonstrates and establishes an optimization of geometric parameters of MR damper using statistical tools, i.e., DoE and FEM results. The proposed method not only saves the time but also the resources for the designing of an optimized MR damper. The process illustrated in this paper will be useful for future automotive design engineers for predicting an optimized damping force of an MR damper.

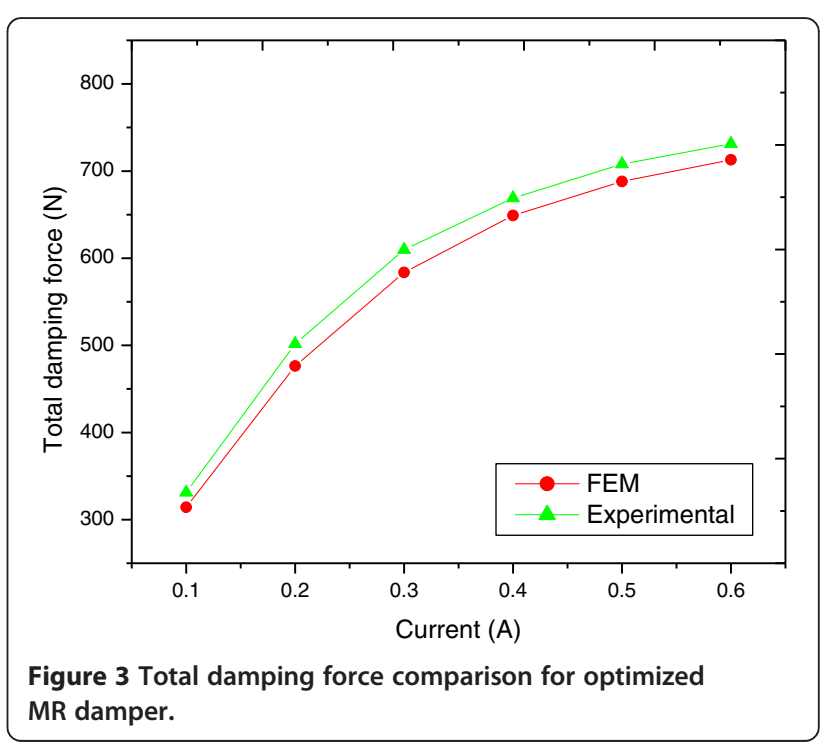




\section{Competing interests}

The authors declare that they have no competing interests.

\section{Authors' contributions}

The work has been done jointly by the two authors. Both authors have read and approved the final manuscript.

Received: 24 August 2014 Accepted: 26 January 2015

Published online: 31 March 2015

\section{References}

S K Mangal and Ashwani Kumar, "Experimental and numerical studies of magneto-rheological (MR) damper" Chinese Journal of Engineering, vol. 2014, 7 pages, 2014, doi:10.1155/2014/915694, Hindawi Publishing Corporation Ashwani, K, \& Mangal, SK. (2012). Properties and applications of controllable fluids: A review. International Journal of Mechanical Engineering Research, 2(1), 57-66

Ashwani, K, \& Mangal, SK. (2014). "Mathematical and experimental analysis of magneto rheological damper". International Journal of Mechanic Systems Engg, 4(1), 11-15.

Carlson, JD, Catanzarite, DM, \& St. Clair, KA. (1996). Commercial Magnetorheological Fluid Devices. International Journal of Modern Physics B, 10(23-24), 2857-2865.

Chang-sheng, ZHU. (2003). A disc-type magneto-rheologic fluid damper. Journal of Zhejiang University science, 4(5), 514-519.

Designing with MR fluids. (1999) Lord Corporation Engineering Note, Thomas Lord Research Center, Cary, NC, USA

$\mathrm{Li}, \mathrm{WH}, \&$ Guo, NQ. (2003). Finite element analysis and simulation evaluation of magnetorheological valve. Journal of Advanced Manufacturing Technology, $21,438-445$.

Parlak, Z, Engin, T, \& Calli, I. (2012). Optimal design of MR damper via finite element analyses of fluid dynamic and magnetic field. Mechatronics The Science of Intelligent Machines, 22, 890-903.

Rabinow, J. (1948). The magnetic fluid clutch. Transactions of the AIEEE, 67, 1308-1315. Rosenfield, NC, \& Werely, NM. (2004). Volume-constrained optimization of MR and ER valves and dampers. Smart Materials and Structures, 13, 1303-1313.

Ross, PJ. (1988). Taguchi techniques for quality engineering. New York: McGraw-Hills Book Company.

Roy, RK. (1990). A primer on Taguchi method. New York: Van Nostrand Reinhold.

H. Wei and N. M. Wereley, Non-dimensional damping analysis of flow mode magnetorheological and electrorheological dampers, Proceedings of ASME 2003 International Mechanical Engineering Congress and Exposition, 2003; Washington, DC; USA, November 15-21, 2003, 265-272.

www.lord.com. http://www.lordfulfillment.com/upload/DS7027.pdf

Zhao-Dong, X. (2012). Da-Huan Jia \& Xiang-Cheng Zhang, Performance tests and mathematical model considering magnetic saturation for magnetorheological damper. Journal of Intelligent Material Systems and structures, 23(12), 1331-1349.

Zhu, X, Jing, X, \& Cheng, L. (2012). Optimal design of control valves in magnetorheological fluid dampers using a nondimensional analytical method. Journal of Intelligent Material Systems and Structures, 24(1), 108-129.

\section{Submit your manuscript to a SpringerOpen ${ }^{\circ}$ journal and benefit from:}

- Convenient online submission

- Rigorous peer review

- Immediate publication on acceptance

- Open access: articles freely available online

- High visibility within the field

- Retaining the copyright to your article

Submit your next manuscript at springeropen.com 